\title{
Potential to attract drivers out of their cars in dense urban areas
}

\author{
Andres Monzon • Luis Alfredo Vega • \\ Maria Eugenia Lopez-Lambas
}

Received: 2 September 2010 / Accepted: 26 August 2011 /Published online: 27 September 2011

(C) The Author(s) 2011. This article is published with open access at SpringerLink.com

\begin{abstract}
Purpose Sustainable mobility urban policies intend reducing car use and increasing walking, cycling and public transport. However, this transfer from private car to these more sustainable modes is only a real alternative where distances are small and the public transport supply competitive enough. This paper proposes a methodology to calculate the number of trips that can be transferred from private car to other modes in city centres.

Method The method starts analyzing which kind of trips cannot change its mode (purposes, conditions, safety, etc.), and then setting a process to determine under which conditions trips made by car between given O-D pairs can be transferable. Then, the application of demand models allow to determine which trips fulfil the transferability conditions. The process test the possibility of transfer in a sequential way: firs to walking, then cycling and finally to public transport. Results The methodology is tested through its application to the city of Madrid (Spain), with the result of only some $18 \%$ of the trips currently made by car could be made by other modes, under the same conditions of trip time, and without affecting their characteristics. Out of these trips, $75 \%$ could be made by public transport, $15 \%$ cycling and $10 \%$ on foot. The possible mode to be transferred depends on the location: city centre areas are more favourable for walking and cycling while city skirts could attract more PT trips.
\end{abstract}

A. Monzon $(\bowtie) \cdot$ M. E. Lopez-Lambas

TRANSYT - Transport Research Center,

Universidad Politécnica de Madrid,

Madrid, Spain

e-mail: amonzon@caminos.upm.es

M. E. Lopez-Lambas

e-mail: melopezlambas@caminos.upm.es

L. A. Vega

Universidad Pedagogica y Tecnologica de Colombia,

Tunja, Colombia

e-mail: 1vegab@tunja.uptc.edu.co
Conclusions The proposed method has demonstrated its validity to determine the potential of transferring trips out of cars to more sustainable modes. Al the same time it is clear that, even in areas with favourable conditions for walking, cycling and PT trips, the potential of transfer is limited because cars fulfil more properly special requirements of some trips and tours.

Keywords Sustainable mobility · Walking · Cycling · Reducing car trips

\section{Introduction}

Cars have gone from being luxury goods to everyday consumer products. Easy to operate and maintain, they have contributed to a substantial increase in mobility, replacing habitual short-distance travel modes like walking or cycling as well as public transport (Mackett \& Robertson [1]; Rietveld [2]; Thorson \& Robusté [3]; Pucher et al. [4]). In addition, they have a significant impact on the environment and foster population dispersal.

The EU Green Paper "Towards a new culture for urban mobility" [5] states that throughout Europe, increased traffic in town and city centres has resulted in chronic congestion, with many adverse consequences such as delays, pollution, noise and other externalities. There is no comprehensive solution to solve this problem. However, alternatives to private car use, such as walking, cycling and collective transport, should form part of the policies enacted to achieve more sustainable mobility patterns. These modes - more efficient in terms of energy-use and zoning, less pollutant and better adapted to the social and economic conditions of the most vulnerable groups - provide a good solution to many of the transport problems of city centres, with the aim of reversing present mobility trends by promoting other modes than car in urban areas. The European Commission's report on bicycle use in the EU [6] 
states that $30 \%$ of trips made in cars in Europe cover distances of less than $3 \mathrm{~km}$ and $50 \%$ are less than $5 \mathrm{~km}$. Therefore, there is a clear potential for transferring these short trips from car to more sustainable modes.

According to May et al. [7], the chief measures for achieving a lower use of cars and boosting public transport (PT), walking and cycling in city centres are the design of tariff-related measures, provision of information systems, traffic management, and enhanced PT vehicles, along with provision of appropriate infrastructure and facilities to ensure that non-motorised modes are a safe, convenient and relevant option. These measures must be applied in an integrated manner so that synergies are produced (Jones [8]) aimed at making alternative transport modes more competitive from the point of view of total trip time and costs perceived, without forgetting that reliability, comfort and convenience are extremely important variables for users.

The aim of this paper is to develop a methodology to analyse the possibility of reversing the trend towards greater car use and returning to city-centre mobility plans based on PT and the so-called soft modes (Fig. 1), without affecting travel time and daily activities. In other words, the main goal is to develop a method to determine how many trips could be transferred to more sustainable modes without changing the current journey limitations (cfr.2) for each trip purpose. However, the magnitude of the transfer potential in a given place will depend to a certain extent on the social, geographical, economic and cultural peculiarities of the city and on certain variables such as the motorisation rate, income, distribution of land use and supply of each mode.

The City of Madrid was used by the authors as a test location for this methodology, as detailed information on travel demand and supply is available together with a set of economic and environmental indicators. Despite the fact that Madrid has made huge investments in PT, the city continues to suffer problems of congestion, noise, traffic

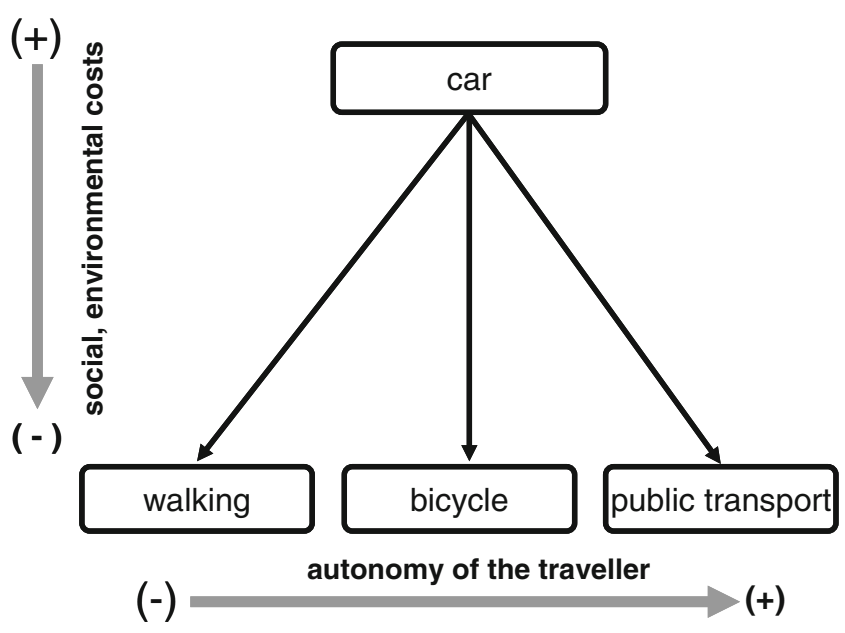

Fig. 1 Transfer of trips from car to public transport and soft modes accidents and delays. Some conclusions are drawn at the end of the paper to illustrate the potential of sustainable transport modes to successfully change the situation. It is necessary not only to change travellers' behaviour but also to apply sustainable policies to modify travel patterns.

\section{Limits to journey transfer from cars to other modes}

However, not all trips can be transferred from cars to more sustainable alternative modes like PT, walking or cycling. The conditions required for a transfer to take place are that the generalised cost (time and cost) not be significantly higher in the alternative mode and that the change of mode not entails any limitation to carrying out the activities generating the trip.

\subsection{Time budget limits}

Journey time is the main limitation of modal choice. This limit is particularly influential in the case of commuter trips. In fact, what normally happens is that any improvements made to road systems foster a greater use of cars. According to Metz [9], travel time tends to remain constant, meaning that, on aggregate, the benefits from improvements to the transport system that have the effect of increasing average speed are taken wholly in the form of greater distances travelled. As a result, it will only be possible to compete effectively with cars when good PT is available and trip distances are adequate for allowing alternative modes to signify a sufficiently competitive supply.

In developed countries, it is not the case that the cost of a trip implies a clear limitation on making the trip by car. For the majority of adults, the use of a car and the cost of the trip do not constitute a deterrent. The main limitation tends to be the cost and difficulty of parking at the destination. Parking control and congestion pricing policies, therefore, are the most effective measures for dissuading travellers from using cars for economic reasons and encouraging the use of other modes. Those having a car at their disposal are very likely to have access to a comprehensive set of alternative transport modes. This is currently the case in most European cities, where PT demand accounts for more than half of total motorised trips [10] with good supply levels and low prices. Bicycle ownership in most western cities is more than 500 cycles per 1,000 inhabitants on average [6]. Therefore, it can be said that in general in European cities, car users do have alternative options for their trips: PT, cycling and walking.

However, only if journey times on alternative modes are appreciably similar will modal transfer take place. As a result, the chief barrier confronting the modal change from private vehicles is journey time (Halden [11]; Mackett \& Robertson [1]; Stradling [12]). This complicates the transfer to PT and non-motorised modes both because of real differences in 
journey time and because of the perception of journey times as longer than are actually required by these modes, as travellers avoid situations perceived as less comfortable.

Perception has a negative effect on the modes considered to be less convenient and comfortable, which in the urban milieu correspond to PT and non-motorised modes. This means that a bias can easily be produced that systematically penalises all modes other than cars (Ortúzar [13]). However, individuals tend to set up a time budget for their journeys (Schafer \& Victor [14]), which forms the basis for establishing a limit for transfers from cars to other modes.

\subsection{Constraints from the activities circuit}

On an urban level, individuals make about three trips a day (Lecler et al., [15]); they will therefore need to make an equal number of decisions concerning the form and characteristics of their travel movements. A large part of these decisions are made for indispensable purposes, such as studies or work, and involve less reasoning, with individuals acting in a quasi-automatic manner. But on many other occasions, the journey mode is determined by earlier actions, by trips that may be made later (Bonnel \& Caubel [16]) or else by the characteristics of the journey itself-accompanying an elderly person, taking a child to school, shopping before returning home, etc. These circumstances may determine that a car be used when otherwise it would not have been.

To analyse these conditioning factors, the concept of a journey as a one-way travel movement from a point of origin, $\mathrm{i}$, to a destination, $\mathrm{j}$, must be replaced by the circuit concept which would consist of a sequence of movements that terminates at the point of origin, such as the home (Bonnel, Caubel \& Massot [17]). If, then, one movement in a circuit requires the use of the car, the other movements are obliged to use this mode as well (Fig. 2).

Applying this principle, the possibility of transferring journeys would be determined by whether or not they form part of a circuit in which one journey requires the use of a car (Henser \& Reyes [18]).

\section{Methodology for calculation of journey transfer potential}

Having established the conditions for modal transfer from a car journey, an analytical methodology was devised for calculating the potential of transfer to each possible alternative mode, in line with the diagram in Fig. 1.

The application area should be a central business district (CBD) where the PT supply is good and where the average distances involved make it possible to make journeys on foot or by bicycle. These conditions normally occur in densely populated districts with a significant supply of alternative modes other than the car. All car journeys in the study area are analysed for their possible transfer to other modes. The potential for transfer is quantified for each travel movement, according to its origin and destination, as a function of the journey characteristics and the competitiveness of the alternative modes. The process follows the decision tree shown in Fig. 3. The starting condition is that the activities system must remain unaltered - established circuits and journey time must be maintained - so that travellers can continue to go about their daily activities without any change whatsoever.

This analysis requires an individual mobility survey in order to disaggregate results on trip-making. The disaggregation level should be sufficient to provide data by zone, time, age, purpose, mode, etc.

Firstly, activities that cannot be done and movements that cannot be made by any other mode than by car must be identified. These include taking the car for trips that tend to be less planned, such as consumer goods shopping (Gärling et al. [19]), and journeys made to accompany individuals with restricted autonomous movement possibilities, such as the elderly and/or handicapped and minors, which dictate even short journeys (Mackett \& Robertson [1]; Mackett, [20]). Also car-dependent are night-time journeys where less PT is available and when security problems increase.

Once these car-dependent journeys have been excluded, the transfer process is applied, which consists of seeking an alternative mode to replace the car for each journey not excluded, following the process illustrated in Fig. 3.

\subsection{Transfer quantification according to travel distance}

The main restrictions for the non-motorised modeswalking and cycling - are distance and journey time, which are interrelated and implicitly include aspects such as

Fig. 2 Examples of interdependent journeys, forming a circuit
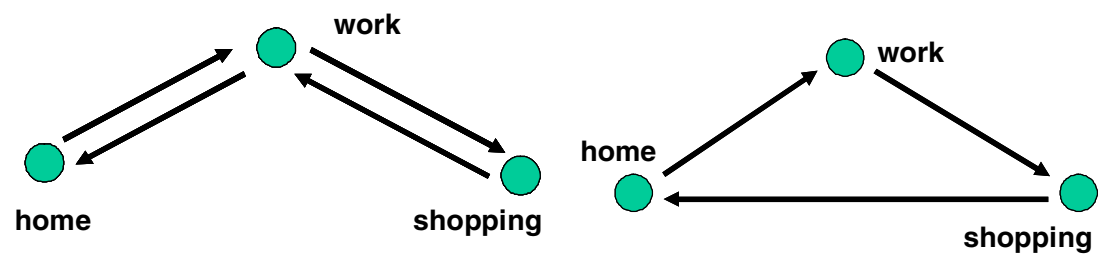


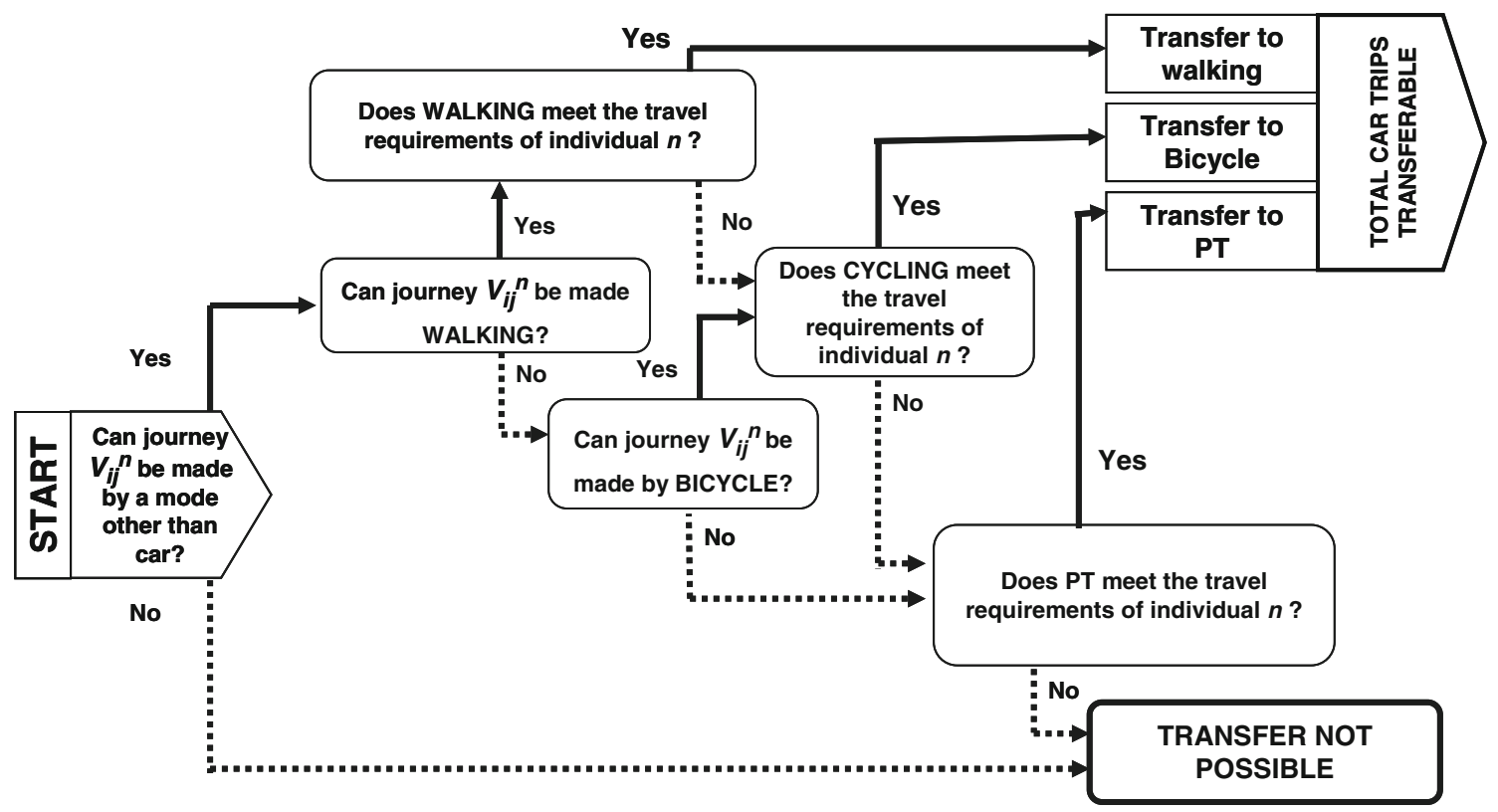

Fig. 3 Decision tree to quantify modal transfer potential

weather, inclines of the terrain, environs, etc. A maximum distance has to be set for journeys on foot or on bicycle as well as an age limit for cycling, owing to the physical condition and skills required. These limits need to be established as a function of the city characteristics and user profile. The trips will first be classified by distance. Whichever car journeys do not exceed the autonomous distance limit for the alternative modes will be susceptible to transfer. If the distance to be travelled on foot for a specific journey exceeds the traveller's autonomous walking capacity, the journey will not be able to be transferred to this mode. In that case, the mode which requires the next greatest autonomous capacity would be turned to: the bicycle. In the event that this mode is not suitable either, the comparison will be made with PT. However, if the next mode does have sufficient autonomy for the particular journey concerned, then analysis would go on to assess competitiveness from the point of view of journey time. In the case of Madrid, the autonomous distance for travelling on foot was set up as the mean average of walking distances stated by the 1996 Mobility Survey: $1.24 \mathrm{~km}$ for young people and $1.47 \mathrm{~km}$ for adults [21].

\subsection{Time-related transfer assessment}

The potential for transfer is assessed in three different ways in relation to journey time. The first is personal autonomy (age and time), referring to the time an individual can comfortably walk or cycle. The second is the difference in journey time in the modes being compared, indicating the direct competitiveness of the mode offered as an alternative for the changeover. The third assessment checks whether the mode transfer would run over the daily time budget for travelling, making it possible to assess the potential for longer journey times without this affecting users' ability to carry out the activities involved.

\subsection{Modelling alternative modal options}

Household mobility surveys provide the reference framework for calculating the transfer potential to other modes. The analysis of origin-destination pairs by trip purpose serves to identify and exclude those trips which cannot be transferred: circuits and trips made to accompany others. It is then necessary to model journey times for the remaining trips using car, PT, cycling or walking. The modelling process is summarised in Fig. 4.

Car trips are assigned to the network according to the Wardrop Principle (Ortúzar [13]), considering trip and parking time. In the case of PT, a specific model must be developed, including localisation of the stops, access and egress time, and commercial speed of each line for each PT mode. The model will output the trip time by PT for each O/D trip currently made by car. For cycling and walking the simulation is easier since all trips are direct from origin to destination. These trip times are established by calculating the shortest possible route in the street network between the origin and the destination of the car trip. Finally, the selection of transferable trips should be made by comparing the results of the trip time models for PT, cycling and walking with the current car trip time of each $\mathrm{O} / \mathrm{D}$ pair recorded in the household survey. This 


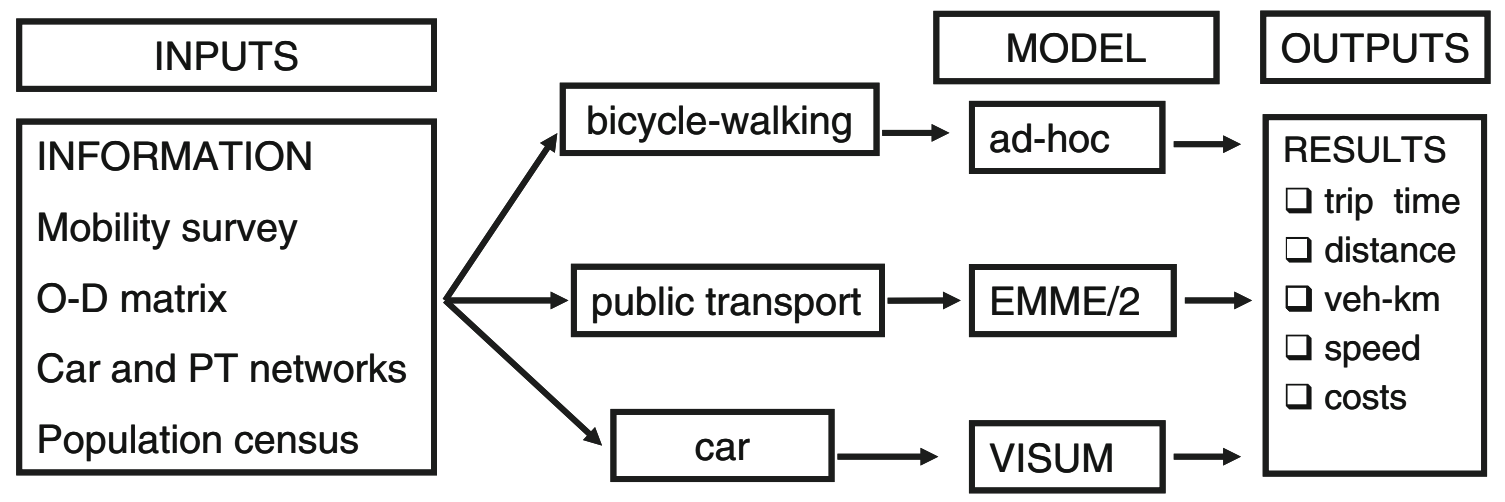

Fig. 4 Modelling process

sequential methodology provides models for alternative mobility patterns while still maintaining the existing activities system because trip time remains constant or decreases in each case. Following the approach of Habib and Miller with regard to random within-day utility variations of activity-travel behaviour [22], the proposed methodology explores the most sustainable mode of transport for each car trip, considering a number of activity constraints including the limit of maintaining journey time.

\section{Potential for reducing car trips in urban areas: the case of Madrid}

The study area chosen was the Madrid Metropolitan Area, specifically trips with their origin and/or destination in the Madrid CBD. This means that the journeys studied take place, at least partially, in the most densely populated zone with the greatest PT provision (Fig. 5).

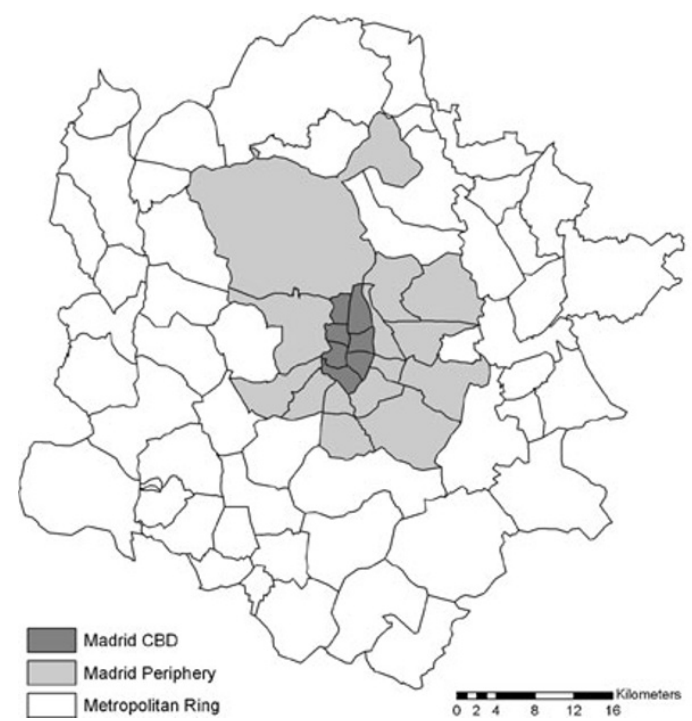

Fig. 5 Study area: Madrid Metropolitan Area

\subsection{Madrid mobility patterns}

Madrid is a city of 3.1 million inhabitants, surrounded by a metropolitan area with a population of 2.3 million. Demographic density varies considerably. In the city centre, Madrid has 51 inhabitants per hectare, whereas within the surrounding metropolitan area the density is only 10.3 inhabitants per hectare. These differences have a substantial effect on mobility. Figure 4 illustrates the changes that have taken place in mobility rates in each mode, comparing the rates from the last two mobility surveys (CRTM [21]; CRTM [23]). The first thing one observes is that the overall mobility rate has been on the rise, increasing from 2.04 to 2.45 between 1996 and 2004. The second is that PT is the most important transport mode in the denser city centre districts whereas the car is predominant in the wider metropolitan area. Thirdly, the number of journeys taken on foot is on the rise in the city centre and is decreasing in suburban areas in favour of car use. Very few journeys are made by bicycle, a mere $0.03 \%$.

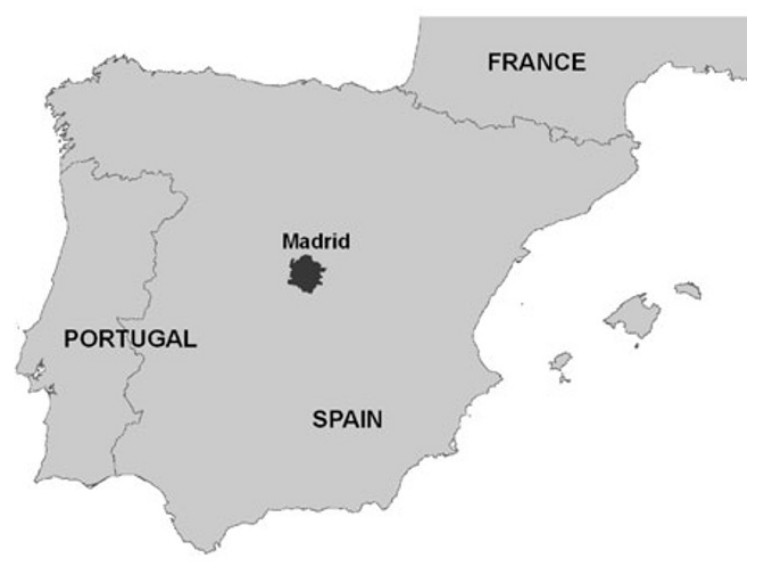




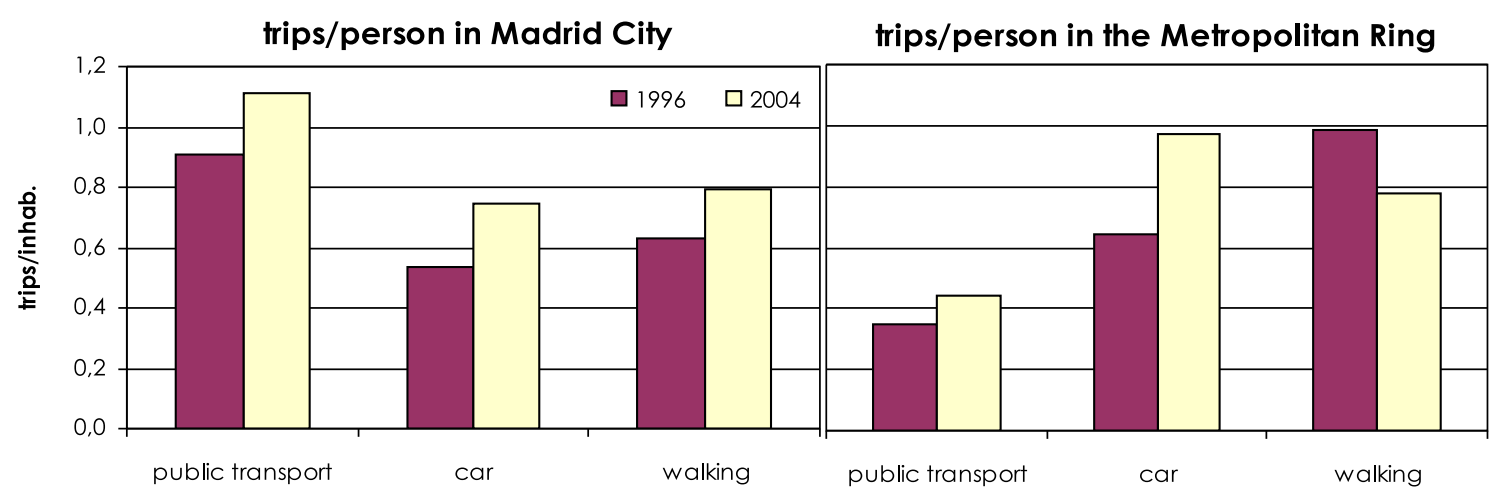

Fig. 6 Modal split distribution in the City of Madrid and Madrid Metropolitan Area

It is clear that modal split patterns depend greatly on population density; however, they are also dependent on other variables such as trip time and length. As Beimborn et al. [24] say, the choice of PT occurs when travellers feel that the PT option is superior to other modes in regard to time, cost, convenience and comfort. By analysing the results of the 2004 mobility survey [25], PT patronage and differences in trip time between PT and car were compared. Figure 6 clearly shows that, in order to increase PT use, the journey time differential as compared to private vehicles needs to be reduced. ${ }^{1}$ In cases where bus journey time is only $40 \%$ higher than by car, PT journeys account for 60 $70 \%$ of motorised travel. However, when PT trip time is twice that by car, PT patronage drops as low as $20 \%$. It is necessary to implement measures to reduce journey times on PT, such as exclusive bus lanes, priority schemes, etc.

Consequently, if PT journeys are to increase, action must be taken with regard to the speed and regularity of PT services in order to be able to compete on a rigorous basis with cars. The Madrid City Council has begun to actively implement measures to improve PT, such as the introduction of bus lanes exclusively for bus and taxi use and the building of a network of transport interchanges for shared use by different PT modes. At the same time, it is applying restrictive measures to private vehicles, especially in the $\mathrm{CBD}$, through a pricing scheme for parking and pedestrianisation of historical zones.

It can be concluded that the City of Madrid has a good mobility performance rating but that car trips are increasing at a faster rate than journeys made by PT or on foot. Bicycle use is marginal. Car journeys predominate in the wider metropolitan area and this figure is growing rapidly, presenting a clear threat for the future of the city in terms of negative environmental effects and other externalities

\footnotetext{
${ }^{1}$ Data for Figs. 6 and 7 come from the 2004 Household Mobility Survey in the Community of Madrid. Dots on the top left of Fig. 7 correspond to dense city centre zone and on the bottom right to the suburban areas.
}

(Bamberg [26]). However, it is hard to know which trips currently made by car could be transferred to other modes or, in other words, exactly how many journeys meet the transfer conditions analysed in the previous section. This is why a methodology has been designed to calculate the potential of transferring trips out of cars.

4.2 Application of the proposed methodology in the Madrid Metropolitan Area

The application of the proposed methodology is composed of three steps: to determine the number of trips that fulfil the limits to transfer. Then, it is necessary to calculate trip time for each of the selected trips for all alternative modes. Finally, the third step is the application of the sequential method to calculate the potential of transfer.

\subsubsection{Transfer limits}

In line with several studies, the following limits were established for the study area in the City of Madrid. First, a

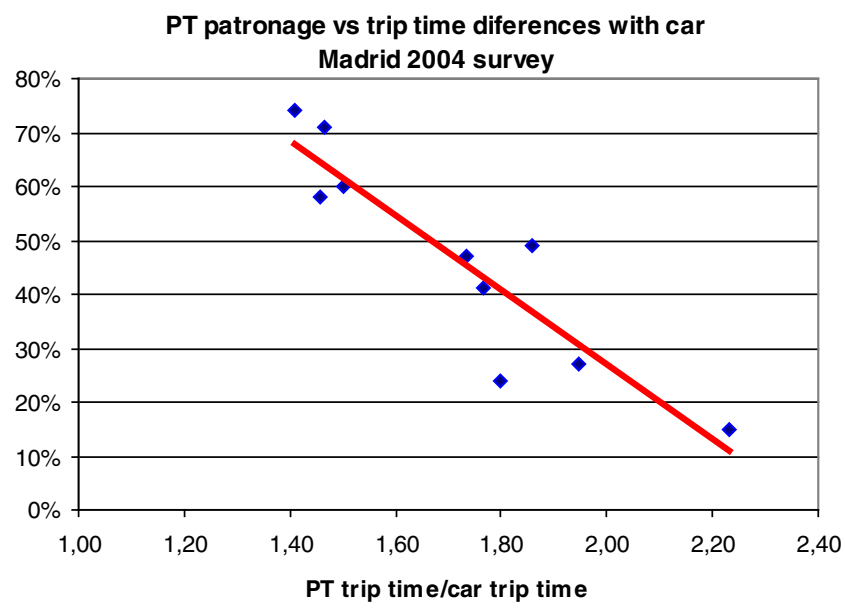

Fig. 7 Public transport patronage vs. trip time differences between public transport and car. Source: Compiled by authors based on data from Madrid Mobility Survey 2004 [23] 
time block was established between 6:00 am and 10:00 pm for security reasons. The maximum distance chosen for journeys on foot was $1.5 \mathrm{~km}$, which is the average for existing walking journeys in the Madrid CBD (CRTM [23]). For cycle journeys, the age limit used was 18 to 50 years (ICE [27]) with a distance limit of $3.5 \mathrm{~km}$ (DeMaio \& Gifford [28]; Litman [29]; ICE [27]). No distance limit was applied to the transfer of trips to PT. After applying these limits, there remain some trips that are transferrable. Therefore the application of this methodology will indicate the minimum number of trips that could be reasonably transferred.

\subsubsection{Madrid modelling process}

The Household Mobility Survey [23] was used to determine the number of trips on each mode that fulfil the requirements stated by the methodology. The iterative transfer calculation method requires knowledge of the journey times for each origin-destination pair on each individual transport network. The coded networks used were the EMME/2 model for PT and VISUM for cars. These models allow us to simulate real trips made by car alongside the alternative option using the demand model for PT. Walking time was determined by applying the average speed of $4.7 \mathrm{~km} / \mathrm{h}$ obtained by the mobility survey. Where cycling is concerned, the lack of representativity offered by the sample meant that data had to be taken from studies done in other cities, and a rate of $9 \mathrm{~km} / \mathrm{h}$ was adopted (Bonnel \& Caubel [16]). The process has been shown in Fig. 4 which indicates the models used for each mode. It is based on the comparison of each car trip with the available alternatives of walking, cycling or PT, following the process indicated in Fig. 3. Although it is possible to transfer some trips from PT to cycling or walking, this was not considered. The target of the study was to determine the potential of transferring trips away from cars in a dense urban area.

Modelling trips in different zones reveals differences in journey time among the different modes, as shown in Fig. 8. The average time for walking trips is less than the average trip time by car, which in turn is less than that on PT modes. However, by analysing the range of variation in the values for each mode, it can be demonstrated that although the average time of PT trips is greater than that of those made by car, for some journeys the opposite is the case, making the transfer from car to PT possible. Similarly, some car journeys can be transferred to walking or cycling trips in central areas.

4.3 Quantification of the potential for transferring car trips to more sustainable modes

Having modelled the journey times, the methodology was applied to determine the percentage of car trips potentially

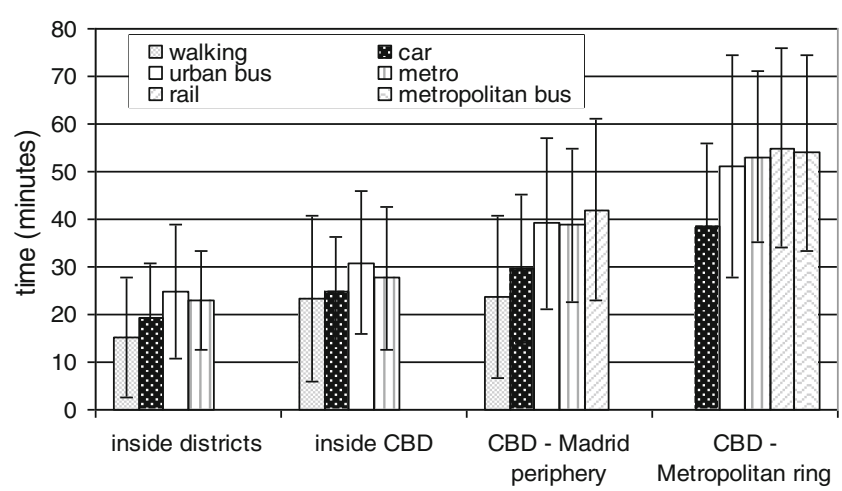

Fig. 8 Average journey times and their standard deviation by mode and zone

transferable to other modes (Fig. 3). First, those journeys that could be made on foot were identified by applying the condition that journey time be less than or equal to that of the car trip. The transfer limits were subsequently applied. All journeys not transferable to walking were analysed following the same procedure to see whether they could be transferred to cycling, and finally, those trips still remaining were analysed to see whether they could be made by PT. The potential for transfer at each stage of the process is summed up in Table 1. Because of distance limitations, analysis of the transferability to walking was only carried out in the CBD. For cycling, all trips within the Madrid city limits were analysed, and for transfer to PT, all the trips in the city centre and the greater metropolitan area were analysed.

These results can be analysed according to the zone where the transfers are produced and also according to overall demand rates expressed in kilometres travelled. The results of this analysis are shown in Table 2. The farther the zone is from the city centre, the higher the number of car-kms saved. As more car trips are transferred to environmentally friendly modes, the number of environmental and other external benefits will increase.

To sum up, it is estimated that, even without varying journey times, a potential does exist for transferring trips by car to alternative modes, especially in the CBD. This potential amounts to some 168,000 trips, equivalent to approximately $18 \%$ of all trips made by car and $11 \%$ of kilometres travelled $[1,227,268]$. $75 \%$ of these trips could be transferred to PT, $15 \%$ to cycling and $10 \%$ could be made on foot.

These results indicate that, even in cities with a high proportion of journeys made on foot and by PT, these percentages could increase even more with an adequate combination of urban transport policies, further restriction of car journeys, greater PT provision and the improvement in the appeal of travelling by PT, on foot and by bicycle (Monzón [30]). The concept of integrated transport strate- 
Table 1 Journey transfer potential from car to sustainable modes

\begin{tabular}{llrrr}
\hline & & Daily trips & \% over total car trips & \\
\hline Trips to transfer to walking & $\mathrm{t}_{\text {car }} \geq \mathrm{t}_{\text {walking }}$ & 31,050 & 17.2 & Trips within the CBD \\
& Fulfil requirements for walking & 16,197 & 9.0 & Trips within Madrid city limits \\
Trips to transfer to cycling & $\mathrm{t}_{\mathrm{car}} \geq \mathrm{t}_{\text {cycling }}$ & 44,907 & 21.9 & 11.5 \\
& Fulfil requirements for cycling & 23,928 & 13.6 & Trips within metropolitan area \\
Trips to transfer to PT & $\mathrm{t}_{\mathrm{car}} \geq \mathrm{t}_{\mathrm{PT}}$ & 128,222 & 18.0 & \\
TOTAL & & 168,347 & \\
\hline
\end{tabular}

gies is not new (May et al. [31]), but few local transport plans can be considered to be truly integrated yet in their approach. They are limited in particular by the resources available, problems in the application of demand management measures, the need to negotiate PT service levels and fares with operators, the lack of understanding of interactions between transport and land use, and the timescale for implementing innovative solutions. As Bertolini \& Le Clercq [32] state, the fundamental dilemma is how to make urban development less dependent upon mobility by car. Therefore, it is necessary to know the potential for transferring journeys away from cars in order to design appropriate TDM measures. These measures should be tailored to achieve real transfers to PT, cycling and walking trips in each zone.

The results also show there is a high potential for short trips to be transferred to walking inside the $\mathrm{CBD}$, as well as to walking and cycling within the city limits, and that PT starts competing with longer car trips in the larger metropolitan area. These results are in line with the findings of Kemperman \& Timmermans [33] and Howley [34] referring to mobility preferences according to urban density.

\section{Conclusions}

Cycling, walking and PT services could be as competitive as cars for a higher number of journeys. However, the car is the most appropriate mode for certain trips with conditioning factors of a social nature (accompaniment of other individuals, security, etc.). This forces travellers not only to make individual travel movements, but also to run on travel circuits in which the unavoidable mode for one part of the journey conditions the mode used in the rest of the circuit. Nevertheless, there is room for developing soft mode trips and PT priority policies in a way that will reduce car journeys in dense city zones to a minimum.

A methodology has been developed to determine how many trips are susceptible to being transferred from car to the more sustainable modes of walking, cycling and PT. This methodology is based on a disaggregated demand model for all travel modes, enabling a comparison to be made between journey times in each transport ratio, transferring to alternative modes the trips in which journey time is less than or equal to the current car journey. Journeys made under certain specific conditions are not deemed to be susceptible to transfer, namely circuits with an unavoidable stage by car, journeys made at night or for the purpose of accompanying other individuals.

Citizens do not always choose the shortest or quickest mode for reaching their destinations (Banister [35]). However, minimising time and cost is seen as 'desirable' and therefore their reduction is directly related to the potential of transferring trips to other modes, within the daily time budget dedicated to travel.

The case of Madrid, where PT patronage is high, enables us to test the methodology and determine the existing potential for transfer to sustainable modes. This potential comes to $18 \%$ of the car movements $(168,347$ trips) currently made to or from the Madrid CBD being transferable in the proportion of $10 \%$ on foot, $15 \%$ by bicycle and $75 \%$ on PT, while still fulfilling all the conditioning factors and without varying journey times.

Table 2 Transfer potential by zone and mode

\begin{tabular}{|c|c|c|c|c|c|c|c|c|}
\hline \multirow[t]{2}{*}{ Zone } & \multicolumn{2}{|c|}{ Walking } & \multicolumn{2}{|l|}{ Cycling } & \multicolumn{2}{|c|}{ Public transport } & \multicolumn{2}{|c|}{ Total Transferable } \\
\hline & trips & $\mathrm{km}$ & trips & $\mathrm{km}$ & trips & $\mathrm{km}$ & trips & $\mathrm{km}$ \\
\hline Within the CBD & 16,197 & 14,052 & 18,848 & 50,330 & 29,801 & 180,769 & 64,846 & 245,151 \\
\hline Within Madrid city limits & & & 5,080 & 14,503 & 90,868 & 826,432 & 95,948 & 840,935 \\
\hline Within metropolitan area & & & & & 7,553 & 141,182 & 7,553 & 141,182 \\
\hline TOTAL & 16,197 & 14,052 & 23,928 & 64,833 & 128,222 & $1,148,383$ & 168,347 & $1,227,268$ \\
\hline
\end{tabular}


The results also indicate that if the prevailing automobileoriented trend in urban development can be reconfigured to become friendlier to PT, walking, and cycling, travellers would be more likely to consider these non driving-modes for travel. This would eventually lead to reduced automobile use and its associated undesirable consequences, as Zang [36] states. Thus, these results will enable measures to be designed to achieve a real transfer to alternative modes with the least possible externalities in each zone, considering the local mobility demand characteristics.

Open Access This article is distributed under the terms of the Creative Commons Attribution License which permits any use, distribution and reproduction in any medium, provided the original author(s) and source are credited.

\section{References}

1. Mackett R, Robertson S (2000) Potential for mode transfer of short trips: Review of existing data and literature sources. Centre for Transport Studies, London

2. Rietveld P (2000) Non-motorised modes in transport systems: a multimodal chain perspective for the Netherlands. Transp Res D 5 (1):31-36. doi:10.1016/S1361-9209(99)00022-X

3. Thorson O, Robusté F (1998) Walking and cycling in the city. World Health Organisation. Environment Pamphlets. Copenhagen

4. Pucher J, Komanoff C, Schimek P (1999) Bicycling renaissance in North America? Recent trends and alternative policies to promote bicycling. Transp Res A 33(7-8):625-654. doi:10.1016/S09658564(99)00010-5

5. Commission of the European Communities (2007) Green Paper: Towards a new culture for urban mobility. COM(2007)551. European Commission, Directorate General for Energy and Transport, Brussels

6. Dekoster J, Schollaert U (1999) Cycling: the way ahead for towns and cities. European Commission, DG XI. Official Publications of the European Communities, Luxembourg

7. May A, Karlstrom A, Marler N, Matthews B, Minken H, Monzón A, Page M, Pfaffenbichler P, Shepherd S (2003) Decision makers guidebook. Strategies for sustainable land use and transport. Prospects D15. European Commission, Brussels

8. Jones, P. (1996). Changing daily urban mobility. Less or Differently? Round Table 102. ECMT, Paris.

9. Metz D (2004) Travel time constraints in transport policy. Transport 157 (2). Proceedings of the Institution of Civil Engineers, United Kingdom, pp 99-105

10. EMTA (2010) EMTA Barometer 2008 of public transport in the European metropolitan areas. http://www.emta.com/IMG/pdf/ba rometer2008.pdf

11. Halden D (2003) Barriers to modal shift. Scottish Executive Social Research. Transport Research Series. Edinburgh

12. Stradling SG (2003). Reducing car dependence. In: Hine J, Preston J (Eds) Integrated futures and transport choices. Bodmin, Cornwall, pp 100-115

13. Ortúzar JD, Willumsen LG (1994) Modelling transport. Wiley, England

14. Schafer A, Victor D (2000) The future mobility of the world population. Transp Res A 34(3):171-205. doi:10.1016/S09658564(98)00071-8

15. Lecler S, Melero T, Cristóbal C (2004) Comparación entre sistemas de transporte público en ciudades europeas. El barómetro
EMTA, VI Congreso de Ingeniería de Transporte - CIT, Zaragoza, España

16. Bonnel P, Caubel D (2002) Lyon 21. Etude de faisabilité d'un système de transport radicalement différent pour la zone dense lyonnaise. Rapport final. LET-ADEME

17. Bonnel P, Caubel D, Massot J (2003) Efficacité spatiale des reséaux de transport dans une perspective de réduction drastique de l'usage de la voiture particulière - application aux zones denses parisienne et lyonnaise. 34 colloque de l'A.S.R.D.L.F

18. Hensher D, Reyes A (2000) Trip chaining as a barrier to the propensity to use public transport. Transportation 27(4):341-361. doi:10.1023/A:1005246916731

19. Gärling T, Gärling A, Johansson A (2000) Household choices of car-use reduction measures. Transp Res A 34(5):309-320. doi:10.1016/S0965-8564(99)00039-7

20. Mackett R (2003) Why do people use their cars for short trips? Transportation 30(3):329-349. doi:10.1023/A:1023987812020

21. CRTM (1998) Encuesta Domiciliaria de Movilidad en día laborable de 1996 en la Comunidad de Madrid. Análisis y síntesis de la movilidad, Consorcio Regional de Transportes de Madrid

22. Habib KMN, Miller EJ (2008) Modelling daily activity program generation. Considering within-day and day-to-day dynamics in activity-travel behaviour. Transportation 35:467484. doi:10.1007/s11116-008-9166-8

23. CRTM (2006) Encuesta Domiciliaria de Movilidad en día laborable de 2004 en la Comunidad de Madrid. Resumen de resultados, Consorcio Regional de Transportes de Madrid

24. Beimborn EA, Greenwald MJ, Jin X (2003) Accesibility, connectivity, and captivity: impacts on transit choice. Transp Res Rec 1835:1-9. doi:10.3141/1835-01

25. Monzón A, Hoz D (2009) Efectos sobre la movilidad de la dinámica territorial de Madrid. Urban 14, 58-71. Departamento de Urbanística y Ordenación del Territorio. Madrid

26. Bamberg S, Rölle D, Weber C (2003) Does habitual car use not lead to more resistance to change of travel mode? Transportation 30)(1):97-108. doi:10.1023/A:1021282523910

27. ICE (2000) The significance of non-motorised transport for developing countries. Strategies for policy development. World Bank, Utrecht

28. DeMaio, P. and Gifford, J. (2004). Smart bikes succeed as public transportation in the United States. Journal of Public Transportation (7) 2: $1-15$.

29. Litman $T$ (2004) Economic value of walkability. Victoria Transport Policy Institute. In http://www.vtpi.org/walkability.pdf. Accessed September 2009

30. Monzón A (2003) Integrated policies for improving modal split in urban areas. 16th ECMT Symposium. Budapest

31. May AD, Shepherd SP, Emberger G, Ash A, Zhang X, Paulley N (2005) Optimal land use transport strategies. Methodology and application to European cities. Transp Res Rec 1924:129-138. doi: $10.3141 / 1924-17$

32. Bertolini L, Le Clercq F (2003) Urban development without more mobility by car? Lessons from Amsterdam, a multimodal urban region. Environ Planning A 35(4):575-589. doi:10.168/a3592

33. Kemperman A, Timmermans H (2009) Influences of built environment on walking and cycling by latent segments of aging population. Transp Res Rec 2134:1-9. doi:10.3141/2134-01

34. Howley P (2009) Attitudes towards compact city living: towards a greater understanding of residential behaviour. Land Use Policy 26:792-798. doi:10.1016/j.landusepol.2008.10.004

35. Banister D (2008) The sustainable mobility paradigm. Transport Policy 15:73-80. doi:10.1016/j.tranpol.2007.10.005

36. Zhang M (2005) Intercity variations in the relationship between urban form and automobile dependence disaggregate analyses of Boston, Massachusetts; Portland, Oregon; and Houston, Texas. Transp Res Rec 1902:55-62. doi:10.3141/1902-07 